\title{
LÍMITES DEL EJERCICIO DEL DERECHO INDÍGENA DESDE LA PERSPECTIVA DEL ESTADO CONSTITUCIONAL DE DERECHO
}

\author{
Limits of the exercise of indigenous law from the perspective \\ of the constitutional Rule of Law
}

Isis Nevai ALBARRÁN GARCÍA

\begin{abstract}
Sumario:
I. Evolución del concepto de Estado II. El Estado Constitucional de Derecho III. Cosmovisión de los sistemas jurídicos indígenas IV. Tensión con los postulados de Derechos Humanos del Estado Constitucional de Derecho V. Discusión VI. Referencias Bibliográficas
\end{abstract}

Resumen: El Estado, como formalización jurídica del pacto político, surge para proteger a sus habitantes de la violencia ejercida por otros individuos o grupos más fuertes. El fortalecimiento de las democracias contemporáneas se encuentra intimamente vinculado a la incorporación de los derechos fundamentales, construcción occidental no siempre compatible con la cosmovisión de los pueblos originarios, lo que genera gran parte de las limitaciones impuestas por el Estado e impide el ejercicio pleno de sus sistemas jurídicos, a pesar de que el respeto a su identidad cultural sea uno de los principales postulados de los derechos humanos y, sobre todo, una característica fundamental de un Estado democrático

Palabras Clave: Estado de Derecho, Derechos humanos, pueblos indígenas, sistemas jurídicos.

Abstract: as legal formalization of the political pact the State, arises to protect the habitants of the violence exerted by other individuals or groups stronger. The strengthening of contemporary democracies is intimately linked to the incorporation of fundamental rights, whose concept corresponds to the vision of Western society and is not always compatible with the worldview of the native peoples, which generates much of the limitations imposed by the State that prevents them from exercising their own legal systems, despite being one of the main postulates of human rights respect for their cultural identity and above all a fundamental characteristic of a rule of law.

Key Words: Rule of Law, Human Rights, Indigenous Peoples, Legal Systems.

\footnotetext{
* Maestra en Administración y Procuración de Justicia por la Universidad Autónoma de Chihuahua; Investigadora honoraria junior en el Proyecto Atlas de los Sistemas Normativos Indígenas en México, (2013-2017), Dr. Isaac González Ruiz, consultor independiente y Antrop. Víctor Hugo Villanueva, Jefe del Departamento de Antropología Jurídica del Instituto Nacional de Antropología e Historia.
} 


\section{Evolución del concepto de Estado}

El Estado, como se encuentra estructurado hoy en día, surge por la necesidad de regular las relaciones de los hombres ${ }^{1}$ en sociedad, con el objeto de protegerlos en su persona y en sus bienes de la violencia ejercida por otros hombres o por otros grupos.

El pacto social surge como forma de asociación que defienda y proteja de toda fuerza común a la persona y a los bienes de cada asociado, y gracias a la cual cada uno, en unión de todos los demás, solamente se obedezca a sí mismo y quede tan libre como antes ${ }^{2}$. Por lo que cada asociado pone a su persona y su a poder bajo la dirección de la voluntad general formando parte de un todo.

El pacto social busca generar una igualdad que equilibre las desigualdades naturales de los hombres. Rousseau considera que sustituye la igualdad natural por la igualdad moral y legítima, eliminando el estado de desigualdad física natural de los hombres, convirtiéndolos en iguales por convención y por derecho ${ }^{3}$.

La vida social del cuerpo político generado con el pacto social requiere de reglas que rijan su funcionamiento, lo que se logra a través de la legislación cuyos objetos principales son la libertad, la igualdad y la seguridad. La libertad porque toda dependencia particular le resta fuerza al cuerpo del Estado y la igualdad porque la libertad no puede subsistir sin ella.

Como ya afirmaba Hobbes son las leyes las que contienen las limitaciones y reglas necesarias para la convivencia y la seguridad por que era indispensable una institución que garantizara el bienestar de todos sin permitir la imposición de la ley del más fuerte.

El establecimiento de las leyes marca para todos los partícipes los límites del derecho de cada agremiado y éstas indudablemente responderán al fin del Estado para el cual fueron creadas.

Tanto Locke como Montesquieu consideraban la libertad como la posibilidad de hacer todo lo que la Ley permitiese, a diferencia de Rousseau cuya concepción de la obediencia a la ley se funda en la libertad, en la voluntad general de adhesión al pacto y por ello a las normas que de él emanen ${ }^{4}$. Respecto a las leyes, Kant en lugar de leyes de la naturaleza y leyes civiles diferencia entre normas morales y jurídicas, sin atender al contenido de las mismas sino por el motivo que hace que un sujeto las obedezca, las normas morales están compuestas por imperativos categóricos, es decir se obedecen porque así debe ser, provienen del interior, mientras que las normas jurídicas son exteriores.

El problema más importante para el género humano a cuya solución está obligado por naturaleza es lograr una sociedad civil que haga cumplir el derecho universalmente 5 .

El Estado aparece como la forma más elevada de la organización humana, es un agente capaz de organizar, o por lo menos de facilitar las relaciones de cooperación y de colaboración entre los hombres, más allá de las relaciones contractuales. Asegura el bien de la sociedad, por

\footnotetext{
${ }^{1}$ Esencialmente, la regulación jurídica, estaba pensada por y para los hombres, por ser éstos los únicos posibilitados para ser propietarios, no porque se infravalorara a las mujeres. Sí ellas pudieran ser propietarias, en el contexto histórico de la obra mencionada, también participarían de la vida civil y política de las sociedad. Véase Kant, Immanuel (1797), Principios metafísicos de la doctrina del derecho, selección, prólogo y notas de Arnaldo Córdova (1968), Nuestros clásicos 33, Universidad Nacional Autónoma de México, México. Actualmente hombres y mujeres son iguales ante la ley, el Estado regula la relación de hombres y mujeres en sociedad.

${ }^{2}$ Rousseau, Jean-Jacques (1762), El contrato social o principios de derecho político, Estudio preliminar y traducción María José Villaverde (1999), $4^{\text {a }}$ edición, Tecnos, España, p. 14.

3 Ibídem, p. 23.

4 FAssò, Guido (1982), Historia de la filosofía del Derecho 2 La edad moderna, Ediciones pirámide, Madrid, p. 247.

${ }^{5}$ Kant, en: Fassò, Ibídem, p. 278.
} 
ello existe un lazo muy estrecho entre el fin del Estado y el del Derecho, [...] el fin del Derecho consiste en garantizar que por la justicia, el orden y la seguridad se creen las condiciones que permitan a los miembros del grupo realizar su bien, el bien de todos, el bien común [... $]^{6}$.

La noción de justicia y la de seguridad deben coincidir en una sociedad bien organizada cuyo fin es el bien común, ya que una seguridad injusta no es tal, es precisamente contraria al derecho, y una injusticia que no ha podido ser asegurada carece de un elemento ${ }^{7}$.

El Estado tiene por objeto favorecer el desenvolvimiento de sus súbditos, conciliando los derechos del individuo con los de la sociedad, por tener un espíritu que lo diferencia de los animales y que le da el derecho a exigir de aquella su respeto y consideración, es la sociedad la que existe para el hombre y no el hombre para la sociedad ${ }^{8}$.

Bajo estos preceptos surge el Estado de acuerdo a las teorías contractualistas, que se ha transformado acorde a la evolución de la sociedad. Zagrebelsky refiere que el siglo XIX se caracteriza por el apogeo del Estado de Derecho: [...] eliminación de la arbitrariedad en el ámbito de la actividad estatal que afecta a los ciudadanos ${ }^{9}$, diferenciándose del régimen de fuerza característico del siglo XVII y del de policía propio del siglo XVIII ${ }^{10}$.

El Estado de derecho representó históricamente un elemento básico de la noción Constitucional liberal, caracterizado por una concepción de la ley como un acto deliberado de un parlamento representativo el cual se manifiesta en los siguientes puntos:

\section{La supremacía de la ley sobre la administración}

\section{La subordinación a la ley de los derechos de los ciudadanos ${ }^{11}$}

La presencia de jueces independientes con competencia exclusiva para aplicar la ley a controversias surgidas entre ciudadanos y entre éstos y la administración del Estado ${ }^{12}$.

El Estado de derecho asume la protección de los derechos de los ciudadanos frente a la arbitrariedad de la administración, por lo que el principio de autoridad estatal experimenta un cambio en su concepción tradicional siendo condicionada por la libertad de la sociedad, bajo un marco de equilibrio que es la ley ${ }^{13}$.

El derecho de nuestro tiempo no consigue contemplar los caracteres que constituían los postulados del Estado de derecho legislativo ${ }^{14}$. En la actualidad no se encuentra posicionada como antes la distinción de los particulares y de la administración frente a la ley, pues frente a los peligros de una libertad sin responsabilidad resurge el paternalismo del Estado, por ello, no es posible partir del principio de legalidad decimonónico. Ejemplo de ello es la regulación jurídica de

\footnotetext{
6 Fur Le, Louis, (1937-1938), “El fin del derecho: bien común, justicia, seguridad”, en: Fur Le, et. al. Los fines del derecho. Bien común justicia seguridad, trad. Daniel Kuri Breña (1997), $3^{\text {a }}$ ed. Manuales Universitarios, Facultad de Derecho, Universidad Nacional Autónoma de México, México, D.F. p. 16.

7 Ibídem, pp. 19-20.

8 Ibídem, p. 24.

9 Zagrebelsky, Gustavo (2009), El derecho dúctil, ley, derechos, justicia, trad. Marina Gascón, novena edición, Trotta, p. 21.

${ }^{10}$ Únicamente desde un punto de vista conceptual, las transformaciones reales han sido paulatinas.

${ }^{11}$ Esta subordinación se fundamenta en que la finalidad de la ley es precisamente salvaguardar los derechos fundamentales de los ciudadanos.

12 ZAGREBELSKY, op. cit. nota 9, p. 23.

${ }^{13}$ Ídem.

${ }^{14}$ Ferrajoli, Luigi (2005), “Pasado y futuro del Estado de Derecho”, en: Neo constitucionalismo(s), edición Miguel Carbonell, segunda edición, Trotta.
} 
la aplicación de la tecnología para la vida, aquello relacionado con las intervenciones artificiales sobre la vida humana (genética, reproducción, trasplante de órganos, interrupción voluntaria del embarazo, suicidio y eutanasia $)^{15}$. Y es cuando cobra vida nuevamente el esquema paternalista estatal en un afán de limitar esta libertad personal por la influencia conservadora de una parte de la sociedad que reprueba estas acciones considerándolas contrarias a la naturaleza.

Esta desaparición de las características clásicas de la ley se encuentra en los caracteres de nuestra sociedad, condicionada por la diversificación de grupos y estratos sociales que participan en el mercado de las leyes. De ahí el incremento de legislaciones sectoriales que causa la crisis del principio de generalidad. Cuando cada actor social considera haber alcanzado fuerza suficiente para orientar a su favor el contenido de la ley, busca la aprobación de nuevas leyes, que da lugar a la contradicción de la generalidad y abstracción de las leyes ${ }^{16}$.

El siglo XX se caracterizó por el apogeo del Estado de derecho mientras que el propio Habermas habla de lo que hasta finales del siglo XIX sería el Estado social mayormente influenciado por la ilustración y la revolución industrial, mientras que en el siglo XX inicia una era de unificación económica mundial que continua acrecentándose hasta nuestros días y que acorde a la concepción de Ferrajoli deberá llevar inevitablemente al constitucionalismo mundial.

Es por tanto innegable la transformación de los viejos conceptos de Estado de Derecho, la evolución de la sociedad ha obligado a replantear elementos fundamentales de la estructura estatal, un lugar importante lo ocupan las relaciones de los derechos con la ley ${ }^{17}$. En el siglo XIX la ley era la primacía de la ley mientras los derechos eran solo pretensiones subjetivas.

La soberanía del Estado se encuentra comprometida por dos aspectos, las estructuras supranacionales; y la composición interna del Estado, desde la multiculturalidad hasta las fuentes del derecho, lo que lleva al planteamiento del derecho dúctil que permitirá la evolución del Estado de Derecho legislativo al Estado Constitucional.

Esta transición se considera necesaria para adecuar las demandas de una sociedad pluralista en la que se exige el respeto del derecho de todos y que se garantice la identidad cultural de cada habitante tal como se contempla en el texto Constitucional.

\section{El Estado Constitucional de Derecho}

El Estado de Derecho de acuerdo a Ferrajoli es contemplado desde dos puntos de vista que divide en dos modelos normativos, el paleo-iuspositivista y neo- iuspositivista ${ }^{18}$.

El paleo ius-positivismo mejor entendido como Estado legislativo de Derecho o Estado legal que surge con el Estado moderno con el monopolio de la producción jurídica, y el neo-iuspositivista con el Estado Constitucional basado en las constituciones rígidas y el control de constitucionalidad de leyes ordinarias cuyos modelos a decir del Ferrajoli reflejan dos experiencias históricas resultado de un triple cambio de paradigma. Los tres paradigmas que identifica son

\footnotetext{
${ }^{15}$ ZaGReBelsky, op. cit. nota 9, p. 36.

${ }^{16}$ Ibidem, p. 37.

${ }_{17}$ Actualmente la ley se encuentra subordinada al respeto a los derechos fundamentales

${ }^{18}$ FerRajoli, op. cit. nota 14, p. 14. 
el de derecho pre-moderno, el Estado legislativo de Derecho y El Estado Constitucional de Derecho ${ }^{19}$.

La primer gran transformación surge del derecho pre-moderno al Estado legislativo con el principio de legalidad como norma de reconocimiento del derecho ${ }^{20}$, en el derecho pre-moderno había una pluralidad de fuentes del derecho como el Imperio, la iglesia, los municipios, entre otras, por lo que en realidad el derecho surgía de la doctrina y la jurisprudencia, es hasta que el Estado tiene el monopolio de la legislación que ocurre el cambio, precisamente con la afirmación del principio de legalidad. Iusnaturalismo y positivismo jurídico pueden ser la base de estos dos opuestos paradigmas. Lo que cambia es el título de legitimación del derecho ya no es la sustancia sino la forma de los actos legislativos lo que les da valide ${ }^{21}$.

El siguiente cambio que experimenta es hacia el Estado Constitucional es la subordinación de la legalidad a la jerarquización de las normas a las Constituciones rígidas. Cambian las condiciones de validez de las leyes dependiendo ya no solo de la forma de producción sino también de la coherencia de sus contenidos con los principios constitucionales ${ }^{22}$.

Finalmente surge una transformación producto del constitucionalismo rígido, representa un límite a los derechos constitucionalmente establecidos a través de [...] prohibiciones y obligaciones impuestas a los poderes de la mayoría que de otra forma serían absolutos [... $]^{23}$, equivale a introducir otra dimensión tanto en la validez como en la naturaleza de la democracia ya que estas prohibiciones y obligaciones constituyen un garante de los derechos de todos frente al abuso del poder.

El Estado constitucional de derecho es el resultado de una evolución del Estado de derecho, un perfeccionamiento de éste, ocasionado por la desintegración de los caracteres del clásico Estado de Derecho, constituye una reestructuración de los postulados más característicos del Estado de derecho, refiere Zagrebelsky que:

Quién examine el derecho de nuestro tiempo seguro que no consigue descubrir en él los caracteres que constituían los postulados del Estado de derecho legislativo. La importancia de la transformación debe inducir a pensar en un auténtico cambio genético, más que en una desviación momentánea en espera y con la esperanza de una restauración ${ }^{24}$.

Bajo este nuevo paradigma de estado que se ha generado, los derechos ya no solo son validos únicamente por el ser sino por el deber ser es decir por los principios y los derechos fundamentales que garantiza; por tanto, el constitucionalismo ha llegado a ser un complemento del Estado de Derecho y se ha extendido al ámbito internacional un ejemplo es la carta de la ONU que tiene un papel como directriz del comportamiento de los Estados, sin embargo aun falta una jurisdicción internacional con la fuerza para sancionar ${ }^{25}$.

Los derechos fundamentales, de acuerdo a la teoría del derecho, son [...] los derechos que están adscritos universalmente a todos en cuanto personas, o en cuanto ciudadanos o personas

\footnotetext{
19 Ídem

${ }^{20}$ Ibídem, p. 15.

${ }^{21}$ Ibídem, pp. 15-17.

${ }^{22}$ Ibídem, p. 18. Ya no se considera válida una ley si atenta contra los derechos fundamentales contenidos en la constitución y en tratados internacionales.

${ }^{23}$ Ibídem, p. 19.

${ }^{24}$ ZaGReBelsky, op. cit. nota 9, pp. 33 y 34.

${ }^{25}$ Ferrajoli, Luigi (2007), Sobre los derechos fundamentales, en: Teoría del Neoconstitucionalismo, ensayos escogidos, edición de Miguel Carbonell, Trotta/Instituto de Investigaciones Jurídicas UNAM, 2007, p. 71.
} 
con capacidad de obrar y que son por tanto indisponibles e inalienables [... $]^{26}$. A este concepto le falta detallar el contenido de estos derechos.

El segundo concepto de derechos fundamentales surge del derecho positivo, según el cual son los que se encuentran establecidos en los ordenamientos legales, en el ámbito internacional serán aquellos contenidos en la Declaración Universal de los Derechos Humanos ${ }^{27}$ y en los demás pactos o convenciones realizados con ese fin.

La tercera definición derivada de la teoría política, más que definir a los derechos humanos intenta establecer [...] cuales derechos deber ser garantizados como fundamentales $[. . .]^{28}$ proponiendo tres criterios axiológicos para distinguirlos. El primero es del nexo establecido entre derechos y paz, es decir, cuales derechos son condición necesaria para la paz; el segundo criterio es el del nexo entre derechos e igualdad en el cual respetando las diferencias se garantice la reducción de las desigualdades; y el tercer criterio se refiere al papel que juegan los derechos fundamentales como leyes del más débil, ya que actúan para proteger al más débil ante la ley del más fuerte que quedaría en su ausencia ${ }^{29}$.

\section{Derechos fundamentales y paz el derecho a la autodeterminación de los pueblos}

En el primer criterio del nexo entre derechos fundamentales y paz se encuentra en la garantía de la paz interna que de acuerdo al paradigma hobbesiano son el derecho a la vida, a la libertad y a la integridad, pero también son los derechos sociales a la supervivencia y en el ámbito internacional cabría una analogía de estos derechos para mantener la paz entre los Estados ${ }^{30}$.

Hay sin embargo otro derecho que debe ser atendido, se trata de la naturaleza y límites del derecho a la autodeterminación de los pueblos, que si bien la Carta de la ONU ${ }^{31}$ no lo define si lo marca como presupuesto para la paz. Se trata de un derecho de autonomía con dos dimensiones: la interna [...] que consiste en el derecho de los pueblos a decidir libremente su estatuto político en el plano del derecho interno [... $]^{32}$. Y la dimensión externa [...] que consiste en el mismo derecho en el plano internacional, así como en el derecho de los pueblos al desarrollo y a la libre disponibilidad de las propias riquezas y recursos ${ }^{33}$. De estas dos, la más problemática para llevarse a cabo es sin duda la externa pues podría entenderse esta autodeterminación como un derecho a volverse Estado cuyas principales funciones para justificar su nacimiento son la unificación nacional y la pacificación interna pero a consecuencia de la globalización estas funciones se han vuelto imposibles y ha expuesto lo insostenible de la pretensión de subsumir pueblos mediante una inclusión forzada en Estados que niegan la diferencias y las identidades comunes ${ }^{34}$.

El derecho de los pueblos a la autodeterminación no es entonces el derecho a constituir un nuevo Estado, es un derecho a pertenecer a él a pesar de diferencias ideológicas o políticas, si los Estados en una situación hipotética se disolvieran y a cambio se formara una comunidad mun-

\footnotetext{
${ }^{26}$ Ibídem, p. 73 .

27 Declaración Universal de los Derechos humanos 1948, disponible en: http://www.un.org/es/universal-declaration-human-rights, consultado el 10 de agosto del 2016.

${ }^{28}$ Ferrajoli, op. cit. nota 25, p. 74.

29 Ídem.

30 Ibídem, p. 75.

${ }^{31}$ Carta de las Naciones Unidas 1945, disponible en: http://www.un.org/es/charter-united-nations/index.html, consultado el 28 de junio del 2016.

${ }^{32}$ Ferrajoli, op. cit. nota, 25, p. 76.

33 Ídem.

${ }^{34}$ Ibídem, pp. $76-77$.
} 
dial bajo el paradigma de un Estado constitucional de derecho habría una igualdad de garantía a los derechos humanos de todos y los conflictos étnicos perderían su razón de $\operatorname{ser}^{35}$.

\section{Derechos fundamentales e igualdad las diferencias culturales}

De la relación entre constitucionalismo y diferencias culturales existe un gran escepticismo ya que se considera a la homogeneidad cultural como un presupuesto de la unificación política, cuando en realidad no es así pues no existe actualmente en la Unión Europea dicha homogeneidad cultural, es la garantía de los derechos fundamentales lo que da el sentido de pertenencia a una comunidad política, igualdad y garantía de los derechos es lo único que se requiere para fundar una nueva identidad colectiva, el constitucionalismo no se opone al multiculturalismo, al contrario es su principal garante ${ }^{36}$.

Es importante que todos los habitantes del Estado sean concebidos como libres e iguales teniendo acceso a los principios de la justicia, es decir que cada persona deberá tener derecho a un esquema de libertades básicas y compatible con el esquema de los demás y eliminar las desigualdades en cuanto a las condiciones de oportunidades ${ }^{37}$, independientemente de su origen étnico.

\section{Los derechos fundamentales como leyes del más débil}

Históricamente los derechos fundamentales han surgido como resultado de luchas contra la opresión o discriminación constituyéndose derechos en defensa de los sujetos más débiles sobre los más fuertes, sean instituciones sociales, políticas o jurídicas, familia, empleadores, entre otros, este criterio axiológico de identificación de los derechos fundamentales resuelve dos dificultades de las teorías de derechos humanos, las antropológicas del relativismo cultural y las sociológicas. La idea de que los derechos fundamentales producidos por la cultura occidental es contradictoria a los preceptos de los sujetos de otra cultura a quienes se les pretenden imponer, y la segunda idea de que la validez de los derechos fundamentales depende del consenso expresado por la ciudadanía en nuestros reglamentos occidentales y no en culturas distintas de la nuestra ${ }^{38}$.

La idea de que todos debamos compartir los valores contenidos en los derechos fundamentales es en realidad errónea, una incomprensión de la doctrina liberal del Estado de derecho, y que el consenso respecto a su aplicación deba corresponder incluso a quienes no comparten los mismos valores culturales para que su aplicación tenga efectividad es también incorrecto, [...] el fundamento axiológico del pacto constitucional está no en el hecho de que ninguno quede excluido de su estipulación -lo que sería imposible y generaría constituciones minimalistas e incluso tal vez regresivas- sino en que se pacte la no exclusión [... $]^{39}$ lo que realmente importa es la aceptación y respeto de la libertad y con ello el respeto a las diferencias culturales ${ }^{40}$.

Este párrafo es el que da sentido a la teoría contractualista contemporánea, como fundamento del Estado ya que no importa que los pueblos originarios no hayan sido involucrados al momento de la creación de la Nación, lo que importa es que dentro de la carta magna se contemple

\footnotetext{
35 Ibídem, p. 79.

${ }^{36}$ Ibídem, pp. 79-81.

37 Rawls, John (2012), La justicia como equidad. Una reformulación, trad. Andrés de Francisco, Paidós, España, p. 73.

${ }^{38}$ Ferrajoli, op. cit. nota 25, p. 82.

${ }^{39}$ Ibídem, p. 86.

${ }^{40}$ Ídem.
} 
este respeto a las diferencias culturales a las que alude Ferrajoli y con ello al principio de la no exclusión.

Hoy el desafío en el mundo globalizado surge ante la necesidad de apegarse a los tratados que han sido ratificados por nuestro país en materia de derechos humanos teniendo la presión de organismos internacionales que impactan en nuestra soberanía al demandar el cumplimiento de lo pactado que hacen pensar como inevitable la perspectiva del constitucionalismo mundial de Ferrajoli y obligan a replantear el derecho y la política pero llevado a un nivel interno haciendo compatible la diversidad cultural pero no desde el punto de vista de occidente sino desde la perspectiva del otro.

\section{Cosmovisión de los sistemas jurídicos indígenas}

Para poder realizar un acercamiento a la cosmovisión de los pueblos indígenas es necesario atender a las consideraciones teóricas del concepto de cosmovisión, que a decir de Zuckerhut aparece con Johana Broda en 1979 entendido como una visión estructurada en la que se combinan nociones sobre medio ambiente y el cosmos, para los años ochenta más que una interpretación el concepto se convierte en representaciones colectivas de la realidad determinadas por las prácticas y el pensamiento de los humanos, que puede tener variantes, cuando existe coincidencia en las ideas dominantes se trata de una cosmovisión única con variantes ${ }^{41}$.

Heidegger en un análisis crítico de una publicación que le precede, realizada por Jaspers, realiza una definición estableciendo que:

[...] la cosmovisión es un elaborado que pertenece totalmente en su sentido de sustancia, de referencia y de ejecución a la estructura fundamental de la experiencia fáctica de la vida. Si nosotros entendemos cada vida, de un particular o de la comunidad, en su totalidad emergida desde una situación espiritual, conservándose y cumpliéndose en ella, entonces la cosmovisión significa: el contexto vivo y concreto de motivación de las posiciones fundamentales, de las decisiones y de los mundos de la vida que domina la situación de una vida ${ }^{42}$.

Este concepto enfatiza el vínculo entre la percepción de la vida en pensamiento y la vida concreta a diferencia de Jasppers quien lo concibe como una mera contemplación de las imágenes del mundo considerando que la cosmovisión no produce conocimiento científico, solo ideas ${ }^{43}$.

En función de este concepto se entiende que la cosmovisión es la forma de concebir e interpretar el mundo de una persona o de una comunidad en un tiempo y lugar determinado, para hablar específicamente de la cosmovisión indígena debemos atender a su concepto del mundo y su gran acercamiento a la naturaleza interrelacionado con sus creencias religiosas, pero además es innegable el impacto que ha tenido sobre su percepción el mundo occidental por lo que inevitablemente se han transformado sus creencias dentro de un proceso de aculturización, eso considerando que ya son muy pocas si no es que extintas las comunidades étnicas que se encuentran en aislamiento y en todo caso serán casos excepcionales.

En general,

\footnotetext{
41 Zuckerhut, Patricia (2007),"Cosmovisión, espacio y género en México Antiguo” en: Boletín de Antropología Universidad de Antioquía, volumen 21, número 38, p. 66.

${ }^{42}$ Mueller Uhlenbrock, Klaus Theodor (2012), "El concepto de la Cosmovision en Jasppers y Heidegger” en: Multidisciplina 13, Humanidades, Universidad Nacional Autónoma de México, Facultad de Estudios superiores de Acatlán, p. 100.

43 Jaspers en ibídem, p. 102. 
[...] el sistema jurídico indígena se caracteriza por poseer concepciones particulares del derecho, la justicia, la autoridad el poder y la representación mediadas por instituciones culturales propias y determinadas por los principios de armonía social y espiritual con la naturaleza, cuya principal fuente es la propia historia cultural, contenida en las palabras y en la memoria de los ancianos, de tal manera que en la mayoría de los pueblos indígenas existe un origen, un espíritu, una función y una utilidad independiente y autónoma del ser humano considerado individualmente ${ }^{44}$.

Un ejemplo es la comunidad Tsotsil Maya ubicada en San Juan Chamula, estado de Chiapas, México, que de acuerdo a la descripción de su vida comunitaria que hace Shilón, cuenta con una filosofía de vida formulada a través de una reflexión de la experiencia humana vivida en la que se mezclan en la vida cotidiana las tradiciones, la religiosidad, el pensamiento mágico y sus principios, para mantener el orden social, si bien no existe en su léxico una traducción del concepto de derechos humanos, si viven bajo su amparo de acuerdo a nuestra visión, pues su código de conducta para obtener un buen vivir contiene valores fundamentales que norman la convivencia como el respeto a la vida, a la integridad, a la propiedad, entre otros ${ }^{45}$.

El mantenimiento del orden social para los tsotsiles busca mantener un orden cósmico como un deber humano y divino para seguir sosteniendo el mundo y la relación entre la comunidad y la naturaleza y cuentan con instituciones encargadas de resolver los problemas suscitados tanto en materia familiar, de tierras, de incumplimiento de responsabilidades comunitarias, civiles, culturales o religiosas, de seguridad o de administración de recursos, teniendo un sistema de administración de justicia oral en el que intervienen todas las partes involucradas y buscan principalmente llegar a acuerdos y reparar los daños.

Cuentan con un organigrama establecido de autoridades y que son designados mediante procesos que son reconocidos como válidos por la comunidad aunque contengan matices de pensamiento mágico pues este es parte de su ideología, un ejemplo de ello es que para ocupar cargos públicos pueden considerar como una razón el hecho de que el solicitante haya soñado que debe ocupar ese cargo; estas autoridades tienen competencia y capacidad para resolver todos los problemas de la comunidad sin embargo el Estado no considera que tratándose de delitos graves deban resolver conforme a su tradición e interviene quitándoles su competencia, argumentando poder garantizar el debido proceso y con ello evitar violaciones de derechos humanos, sin embargo que tan garantista puede ser el debido proceso cuando quien debe ser sometido a él no lo considera justo y lo que contempla como tal no es permitido y que tan efectivos serán los resultados cuando las penas que se imponen por el Estado no cumplen con la reparación de los daños causados a los directamente ofendidos ni a la comunidad a la que pertenecen.

A pesar de que el Estado ha hecho el reconocimiento jurídico incluso a nivel constitucional existen lagunas, normativas culturales y doctrinales, ¿será una cuestión de ignorancia estatal? $\mathrm{o}$ ¿tal vez de conveniencia a intereses económicos que pueden verse afectados si se hace el pleno reconocimiento de los derechos de los pueblos originarios? ¿acaso es el miedo de perder el

\footnotetext{
44 Pepinosa Bravo, Héctor Eduardo ()2012), "Una mirada al concepto de justicia desde la cosmovisión indígena de los pastos”, revista Facultad de Derecho y Ciencias Políticas, vol. 42, núm. 117, Medellín, Colombia, julio- diciembre, p. 490.

45 Shilón, Marcos (2012), Los sistemas normativos en San Juan Chamula, Programa Universitario México Nación Multicultural, en línea, disponible en: http://www.nacionmulticultural.unam.mx/portal/acervos_sistemas_informacion/sidi.html consultado el 20 de septiembre del 2016.
} 
dominio sobre la población aceptando las diferencias y que ello implique una falsa pérdida de soberanía? o tal vez un poco de todo.

De seguir ante esta invisibilidad estatal se corre el riesgo de que perezcan poco a poco los pueblos originarios ante una necesaria homogeneidad de la población como ha sucedido ya con algunas variantes de poblaciones indígenas que han desaparecido en nuestro país.

\section{Tensión con los postulados de Derechos Humanos del Estado Constitucional de Derecho}

De la aplicación de los sistemas jurídicos autóctonos que se han implementado tanto en el ámbito nacional como internacional se han identificado varios aspectos que generan polémica, entre ellos: definición del límite del ejercicio de este derecho, al respecto Rivera comenta:

Debe ser asumido como un reto para lograr un avance en la concepción oficial de los derechos humanos, logrando insertar la perspectiva emergente de la particularidad de los derechos indígenas - de la diversidad cultural-a la perspectiva universal, cabe señalar que un eventual conflicto entre la dignidad humana y los derechos humanos consagrados por las constituciones nacionales y los tratados internacionales con las prácticas culturales indígenas o sistemas legales indígenas no debe resolverse a partir de una visión unilateral sino a partir de una visión intercultural $^{46}$.

En el mismo sentido Julio considera que el límite de los sistemas normativos indígenas es tal como Colombia lo ha hecho, respetando el más alto grado posible de autonomía en las decisiones adoptadas por las autoridades tradicionales estableciendo mediante un consenso intercultural ciertas prohibiciones mínimas como son la prohibición de pena de muerte, esclavitud, tortura $y$ destierro ${ }^{47}$ y si bien aún no es claro el límite, a través de la experiencia de los países que vayan implementando los sistemas jurídicos indígenas se resolverá esta problemática.

Otro problema es la cuestión de la competencia, tratándose de asuntos en los que intervengan más de una persona y alguno de ellos pertenezca a algún pueblo originario. Al respecto Romero propone:

El Principio de igualdad procesal como criterio de interpretación diciendo que cuando surgen problemas en la determinación del procedimiento aplicable debería resolverse considerando el contenido del principio de igualdad procesal y determinando cuál procedimiento garantiza de mejor forma el debido proceso en el conflicto particular, ya que este principio apunta a conceder a todas las partes de un proceso los mismos derechos, posibilidades y cargas $^{48}$.

Dejando la interrogante sobre si será ese el criterio adecuado para decidir sobre el procedimiento aplicable. Existen limitantes para la plena aplicación de los ordenamientos jurídicos indígenas ya que éstos deben constreñirse a una serie de candados como los llama Rodríguez: a)

\footnotetext{
${ }^{46}$ Rivera Santivañez, José Antonio (2013), en: "Simposio Pluralismo Jurídico y Derechos Humanos”, Julio Estrada, Alexei, et. al. Revista Anuario de Derechos Humanos, Chile, Universidad de Chile, 9, p. 81.

${ }^{47}$ Ibídem, p. 8 o.

${ }^{48}$ Romero Seguel, Alejandro (2012), "La Adecuación del Procedimiento en Materia de Derecho Indígena”, Revista Chilena de Derecho, Chile, 39.
} 
La permisión expresa de su aplicación por la ley estatal; b) La no contravención del orden público estatal, $y$; c) la no contravención a los derechos humanos internacionalmente reconocidos ${ }^{49}$.

En los Estados con anhelos constitucionales democráticos, es clara la existencia del derecho de los pueblos y comunidades indígenas a ejercer su propio derecho y que éste se encuentra reconocido ampliamente dentro del derecho internacional pero esto no ha sido suficiente, por ejemplo, la Constitución Mexicana contempla en su artículo segundo el ejercicio de su autonomía de los pueblos originarios, sin embargo esto no ha logrado trasladarse a la realidad social. Es necesario analizar el paradigma constitucional contemporáneo y generar un cambio estructural para lograr la coexistencia de dos sistemas jurídicos, por un lado el derecho oficial positivo y por otro el derecho de los pueblos originarios.

La concepción de los derechos fundamentales se modifica a raíz de la segunda guerra mundial, se asimila desde la afirmación de que [...] nunca en el futuro los seres humanos deberían ser víctimas de discriminación por sus diferencias particulares ${ }^{5}$. La concepción de la jurisprudencia internacional deja de ser colectiva y privilegia a las personas haciéndolas detentadoras de los derechos humanos ${ }^{51}$.

En 1978 en la declaración sobre la Raza y los Prejuicios Raciales, en el segundo párrafo del artículo primero establece: Todos los individuos y los grupos tienen derecho a ser diferentes a considerarse y ser considerados como tales. Este texto se trasladó literalmente a la Declaración de la UNESCO de Principios sobre Tolerancia de $1995^{52}$.

Estas declaraciones no deberán contradecir el principio de igualdad enunciado en la Declaración Universal de los Derechos Humanos, es decir el derecho a la cultura y de las minorías culturales tienen como límite los demás derechos fundamentales ${ }^{53} \mathrm{y}$ volvemos a la interrogante de si los derechos fundamentales son derechos de todos porque en la cosmovisión de los pueblos indígenas ni siquiera existen y por tanto no hay forma de conceptualizarlos ni de que sean comprendidos del modo en que la cultura occidental los concibe.

Así mismo es importante analizar las razones por las cuales desde la perspectiva del derecho oficial se consideran violatorias de derechos humanos algunas de sus penas, ya que visto desde la perspectiva del otro ${ }^{54}$ las penas que el Estado impone carecen de impacto social y no reparan el daño ni a la víctima ni a la sociedad, debemos ser capaces de entender la cosmovisión indígena o cuando menos no juzgar su capacidad de mantener el equilibrio en sus comunidades permitiendo la aplicación de sus propios sistemas jurídicos cuyo único límite debiera ser acaso la prohibición de pena de muerte, tortura y mutilación respetando el marco mínimo de derechos humanos sobre el que se encuentra constituido el país, pues no se trata de construir nuevas naciones sino de respetar su identidad y su pertenencia al Estado Mexicano.

\footnotetext{
${ }^{49}$ Rodríguez Martínez, Elí, (2013), El reconocimiento de los ordenamientos jurídicos indígenas en el derecho internacional, con especial referencia al Derecho Mexicano. ¿Realidad o utopia?”. EAFIT Journal of International Law, Colombia, p. 81.

${ }^{50}$ Mazzarese, Tecla (2014), "El derecho a ser diversos en las sociedades multiculturales", en: XXVII Jornadas Argentinas de Filosofía Jurídica y Social, multiculturalismo, interculturalidad y derecho, coords. Jorge Eduardo Douglas Price y Diego Duquelsky Gómez, Infojus, Universidad Nacional del Rosario, Argentina, p. 5.

${ }^{51}$ Santiago Monzalvo, Alejandro (2011), "La situación formal de los derechos de los pueblos indígenas, algunas inconsistencias argumentativas y formalistas", Alegatos, núm. 77, Departamento de Derecho, Universidad Autónoma Metropolitana, p. 134.

${ }^{52}$ Romero, op. cit. nota 48, p. 13.

${ }^{53}$ Ibidem, p. 14.

54 Así llama De Sousa Santos a tomar en cuenta la cosmovisión indígena, cfr. Sousa Santos, Boaventura De (2010), Refundación del Estado en América Latina perspectivas desde una epistemología del sur, México, Universidad de los Andes, Siglo del hombre editores, Siglo XXI editores.
} 


\section{Discusión}

El Estado constitucional debe ser promotor y garante de los principios del modelo en el que se funda, pues así como en algún momento se creyó que la pluriculturalidad plasmada en la reforma Constitucional de enero de 1992 sería suficiente, o que la reforma del 14 de agosto del 2001 lo lograría, y no obstante que la reforma del 10 de junio del 2011 configuró un gran avance en la materia esto no ha sido suficiente para que el Estado garantice de facto la autonomía y libre determinación de los pueblos originarios.

Más que un multiculturalismo liberal que reconoce sistemas de derecho distintos al de la cultura dominante, siempre y cuando no interfieran con ella se debe apostar no solo por el reconocimiento de la diversidad sino por el enriquecimiento mutuo entre las distintas culturas.

No se trata de establecer como derecho oficial en nuestra Constitución cada uno de los sistemas normativos, pues ni siquiera se tiene aún una base de datos con el atlas normativo nacional $^{55}$, sino de la apertura a que permita garantizar la autonomía de cada de las comunidades indígenas y de reconocer como válido el enjuiciamiento de cualquiera de sus integrantes que se reconozca como indígena bajo sus propios sistemas jurídicos ya el Estado no es capaz de contemplar la amplia amalgama de sistemas y seria pernicioso querer llevarlo a cabo de ese modo.

Inclusive habría que realizar un profundo análisis de los límites impuestos por los derechos humanos, pues el cometido de éstos es causar el menor sufrimiento y ¿no será causar mayor sufrimiento el querer imponer la visión occidental de los límites de los derechos humanos justo en aras de querer evitarlo?, ¿no es más humillante considerar a un pueblo como incapaz de determinar sus propios límites?

Y por tanto establecer éste como límite sería injusto e inequitativo constreñir el ejercicio de su propio derecho a un fundamento teórico para ellos incomprensible ¿cómo se esperaría entonces que ellos supieran como aplicar estas limitantes? o entonces ¿se vería el Estado forzado a imponer nuevamente su concepción del derecho violentando el ejercicio de los sistemas jurídicos indígenas?

\section{Referencias Bibliográficas}

Córdova, Arnaldo (1968), “introducción”, en: Immanuel Kant (1797), Principios Metafísicos de la Doctrina del Derecho, selección, prólogo y notas de Arnaldo Córdova, Nuestros clásicos 33, Universidad Nacional Autónoma de México, México.

Delos, J.T. (1937-1938), “Los fines del derecho: bien común, seguridad, justicia” en: Fur le, et. al. Los fines del derecho: bien común justicia seguridad, trad. Daniel Kuri Breña (1997), $3^{\text {a }}$ ed., Manuales Universitarios, Facultad de Derecho, Universidad Nacional Autónoma de México, México, D.F.

Ferrajoli, Luigi (2011), Principia Iuris. Teoría del Derecho y de la Democracia, Tomo 2, Teoría de la Democracia, Trotta, Madrid, España.

\footnotetext{
55 Este trabajo lo estaba realizando el Instituto Nacional de Antropología e Historia con su proyecto de Atlas de los Sistemas Normativos Indígenas en México, en línea, disponible en: http://www.antropologia.inah.gob.mx/ index.php/2013-07-20-01-58-22/proyectos-colectivos/2013-07-25-06-13-09/2013-07-31-20-12-27.
} 
(2007), Sobre los derechos fundamentales, en: Teoría del Neoconstitucionalismo, ensayos escogidos, edición de Miguel Carbonell, Trotta/Instituto de Investigaciones Jurídicas UNAM, 2007.

(2005), "Pasado y futuro del estado de Derecho", en: Neoconstitucionalismo(s), Ed. Miguel Carbonell, Trotta, Madrid, España

FAssò, Guido (1982), Historia de la filosofía del Derecho 2 La edad moderna, Ediciones pirámide, Madrid.

Fur Le, Louis, (1937-1938), “el fin del derecho: bien común, justicia, seguridad”, en: Fur le, et. al. Los fines del derecho. Bien común justicia seguridad, trad. Daniel Kuri Breña (1997), $3^{\text {a }}$ ed. Manuales Universitarios, Facultad de Derecho, Universidad Nacional Autónoma de México, México, D.F.

Hobbes, Thomas (2003), Leviatán, ed. Losada, Argentina.

Julio Estrada, Alexei; Rivera Santivañez, José Antonio; Torbisco, Neus; Valiente López, Aresio e Yrigoyen Fajardo, Raquel (2013) "Simposio Pluralismo Jurídico y Derechos Humanos”, Revista Anuario de Derechos Humanos, Chile, Universidad de Chile, 9.

Kant, Immanuel (1797), Principios Metafísicos de la Doctrina del Derecho, selección, prólogo y notas de Arnaldo Córdova (1968), Nuestros clásicos 33, Universidad Nacional Autónoma de México, México.

Mazzarese, Tecla (2014), "El derecho a ser diversos en las sociedades multiculturales", en: XXVII Jornadas Argentinas de Filosofía Jurídica y Social, multiculturalismo, interculturalidad y derecho, coords. Jorge Eduardo Douglas Price y Diego Duquelsky Gómez, Infojus, Universidad Nacional del Rosario, Argentina.

Mueller Uhlenbrock, Klaus Theodor (2012), "El concepto de la Cosmovision en Jasppers y Heidegger” Multidisciplina 13 Humanidades, Universidad Nacional Autónoma de México, Acatlán.

Pepinosa Bravo, Héctor Eduardo (2012), "Una mirada al concepto de justicia desde la cosmovisión indígena de los pastos”, Revista Facultad de Derecho y Ciencias Políticas, vol. 42, núm. 117, Medellín, Colombia, julio-diciembre.

Rousseau, Jean-Jacques (1762), El contrato social o principios de derecho político, Estudio preliminar y traducción María José Villaverde (1999), 4ª edición, Tecnos, España, p. 4.

RAwLS, John (2012), La justicia como equidad. Una reformulación, trad. Andrés de Francisco, Paidós, España.

Rodríguez Martínez, Elí, (2013), “El reconocimiento de los ordenamientos jurídicos indígenas en el derecho internacional, con especial referencia al Derecho Mexicano. ¿Realidad o utopia?". EAFIT Journal of International Law, Colombia. 
Romero Seguel, Alejandro (2012), "La Adecuación del Procedimiento en Materia de Derecho Indígena”, Revista Chilena de Derecho, Chile, 39.

Santiago Monzalvo (2011), Alejandro, La situación formal de los derechos de los Departamento de Derecho, Universidad Autónoma Metropolitana, núm. 77.

Shilón, Marcos (2012), Los sistemas normativos en San Juan Chamula, Programa Universitario México Nación Multicultural, en línea, disponible en : http://www.nacionmulticultural.unam.mx/portal/acervos_sistemas_informacion/sidi.html consultado el 20 de septiembre del 2016,

Sousa Santos, Boaventura De (2010), Refundación del Estado en América Latina perspectivas desde una epistemología del sur, México, Universidad de los Andes, Siglo del hombre editores, Siglo XXI editores.

Zagrebelsky, Gustavo (2009), El derecho dúctil, ley, derechos, justicia, trad. Marina Gascón, novena edición, Trotta.

Zuckerhut, Patricia (2007), “Cosmovisión, espacio y género en México Antiguo” en: Boletín de Antropología Universidad de Antioquía, volumen 21, número 38. 